\title{
Salicylates Measurement
}

National Cancer Institute

\section{Source}

National Cancer Institute. Salicylates Measurement. NCI Thesaurus. Code C147431.

The determination of the amount of salicylates present in a sample. 